\title{
Glue Embolization of Gastroesophageal Varices during Transjugular Intrahepatic Portosystemic Shunt (TIPS) Improves Survival Compared to Coil-only Embolization-A Single-Center Retrospective Study
}

\author{
Karsten Wolter $^{1}$ (D) Michael Praktiknjo ${ }^{2} \cdot$ Julia Boie $^{1} \cdot$ Georges Decker $^{1}$. \\ Jennifer Nadal $^{3}$ - Christian Jansen ${ }^{2}$ Wiebke I. Y. Keller ${ }^{4}$ Carsten Meyer ${ }^{1}$. \\ Jonel Trebicka $^{5} \cdot$ Ulrike Attenberger $^{1} \cdot$ Daniel Thomas $^{1}$
}

Received: 25 November 2020/ Accepted: 16 April 2021 / Published online: 21 May 2021

(C) The Author(s) 2021

\begin{abstract}
Purpose To compare the safety and effectiveness of coil versus glue embolization of gastroesophageal varices during transjugular intrahepatic portosystemic shunt (TIPS) creation.

Materials and Methods In this monocentric retrospective study 104 (males: 67 (64\%)) patients receiving TIPS with concomitant embolization of GEV and a minimum followup of one year (2008-2017) were included. Primary outcome parameter was overall survival (6 week; 1 year). Sixweek overall survival was assessed as a surrogate for treatment failure as proposed by the international Baveno working group. Secondary outcome parameters were development of acute-on-chronic liver failure (ACLF), variceal rebleeding and hepatic encephalopathy (HE). Survival analysis was performed using Kaplan-Meier with log-rank test and adjusted Cox regression analysis.

Results Indications for TIPS were refractory ascites $(n=33)$ or variceal bleeding $(n=71)$. Embolization was
\end{abstract}

Karsten Wolter and Michael Praktiknjo contributed equally.

Karsten Wolter

karsten.wolter@ukb.uni-bonn.de

1 Department of Radiology, University Hospital Bonn, Bonn, Germany

2 Department of Internal Medicine I, University Hospital Bonn, Bonn, Germany

3 Department of Medical Biometry, Computer Science and Epidemiology, University Hospital Bonn, Bonn, Germany

4 Department of Marketing / Market Data Analysis, University of Tübingen, Tübingen, Germany

5 Department of Internal Medicine I, University Hospital Frankfurt, Frankfurt, Germany performed using glue with or without coils $(n=40)$ (Group G) or coil-only $(n=64)$ (Group NG).

Overall survival was significantly better in group $G$ ( $\mathrm{p}=0.022 ; \mathrm{HR}=-3.333)$. Six-week survival was significantly lower in group NG ( $\mathrm{p}=0.014 ; \mathrm{HR}=6.945)$.

Rates of development of ACLF were significantly higher in group $\mathrm{NG}$ after 6 months $(\mathrm{NG}=14 ; \mathrm{G}=6 ; \mathrm{p}=0.039$; $\mathrm{HR}=3.243)$. Rebleeding rates $(\mathrm{NG}=6 ; \mathrm{G}=3 ; \mathrm{p}=0.74)$ and development of $\mathrm{HE}(\mathrm{NG}=22 ; \mathrm{G}=15 ; \mathrm{p}=0.75) \mathrm{did}$ not differ significantly between groups.

Conclusion Usage of glue in embolization of GEV may improve overall survival, reduce treatment failure and may be preferable over coil embolization alone.

Keywords Liver cirrhosis - Portal hypertension · Variceal hemorrhage $\cdot$ Embolization · TIPS

\section{Introduction}

Liver cirrhosis is a major healthcare burden with prevalence values of about 250 per 100.000 inhabitants in western countries. The main etiological factors are alcohol, viral hepatitis and non-alcoholic steatohepatitis (NASH) particularly in western countries [1,2]. Development of clinical significant portal hypertension (CSPH) in cirrhosis leads to life-threatening complications such as hemorrhage from gastroesophageal varices (GEV) and refractory ascites with consecutive risk of spontaneous bacterial peritonitis, which define acute decompensation episodes and may induce acute-on-chronic liver failure (ACLF) [3-5]. Creation of a transjugular portosystemic stent shunt 
(TIPS) in variceal hemorrhage and refractory ascites can improve survival in selected patients [6-9]. During TIPS collateral vein embolization may further reduce rebleeding rate [10] and rates of hepatic encephalopathy (HE) [11, 12] development. Moreover, a reduction of the collateral blood flow via varicose vessels may improve TIPS flow and thereby TIPS patency $[13,14]$. The hypothesis that embolization of shunts might have an impact on patient outcome, is also supported by the fact that the presence of spontaneous portosystemic shunts (SPSS) has recently been shown to increase rates of decompensation [15]. Recently, a multicenter study showed a significant association of the total area of spontaneous portosystemic shunts (SPSS) with mortality and HE development [16].

Methods of embolization are not standardized, and different materials have been used. A current meta-analysis did not show clear results in favor of one method or the other, underscoring the need for further investigation in this regard [10]. Currently, endovascular coil embolization, glue (n-butyl-2-cyanoacrylate) and vascular plugs are the most common techniques for variceal embolization. The principles of these methods are substantially different. While endovascular coils and plugs obstruct larger afferent vessels, glue penetrates into the peripheral network of shunting vessels and leads to complete occlusion of these collaterals [17].

Vascular plugs and coils seem to be similarly effective [18]; however, a study comparing the effectiveness of glue embolization versus coils has not been performed so far.

The aim of this study was to compare the safety and effectiveness of coil versus glue embolization of gastroesophageal varices during transjugular intrahepatic portosystemic shunt (TIPS) creation.

\section{Materials and Methods}

In this monocentric retrospective study we included 104 patients (Table 1) from the prospective NEPTUN cohort (clinicaltrials.gov identifier NCT03628807) of which several subgroups have previously been reported by Jansen et al. [19], Praktiknjo et al. [20] and Lehmann et al. [21]. These previous reports focused on liver stiffness (collagen type III and IV remodeling) with regard to systemic inflammation markers and liver failure in patients receiving TIPS. None of these reports evaluated different interventional techniques or methods of embolization.

Written patients informed consent and ethics board approval were obtained.

The detailed inclusion criteria were (Table 2): age above 18 years, decompensated liver cirrhosis, clinically significant portal hypertension (CSPH) (hepato-portal venous gradient (HPVG) $>10 \mathrm{mmHg}), \quad$ successful TIPS establishment with PTFE-covered stent endoprosthesis, embolization of gastroesophageal varices and a minimum follow-up period of one year (patients who were lost to follow-up during one year after embolization were excluded from the study). Between 2008 and July 2017, 378 patients received a primary TIPS procedure with PTFEcovered endoprosthesis at our facility. In total, 155 patients received concomitant embolization during TIPS. In total, 51 patients were excluded due to follow-up period of less than one year. In total, 104 patients (67 males; 37 females; $p=0.69$ ) met our inclusion criteria (Fig. 1). Acute-onchronic liver failure (ACLF) was defined as suggested by European Association for the Study of the Liver (EASL) guideline [5, 22], which represents laboratory parameters of liver, kidney and coagulation systems as well as cardiopulmonary parameters and hepatic encephalopathy.

Primary outcome parameters were six-week and oneyear survival. Six-week overall survival was assessed as a surrogate for treatment failure as proposed by the international Baveno working group [23]. Secondary outcome parameters were treatment failure, ACLF development, variceal rebleeding and hepatic encephalopathy (as per West Haven criteria). Patients were divided into two groups: glue embolization \pm coils (group $\mathrm{G}$, glue) and coil-only embolization (group NG, no glue).

\section{Statistics}

Since MELD, age and indication for TIPS are known factors that influence the outcome and were not evenly distributed between the groups, Cox regression analysis has been adjusted for these parameters.

Survival analysis was performed using Kaplan-Meier curves with log-rank tests as well as adjusted Cox regression analysis, group comparisons by $\mathrm{t}$ tests for independent samples (for patient age), Fishers exact test for TIPS indication as well as Mann-Whitney $\mathrm{U}$ test for all other single parameters. Statistical analysis and data plotting were performed using SPSS 27 (IBM, New York, USA).

\section{TIPS and embolization procedure}

The procedures were performed by two interventionists (DT, CM) - both with more than 10 years of experience in interventional radiology. Before TIPS a contrast-enhanced CT scan was performed for procedure planning in order to discern the vascular anatomy (splenorenal shunt; portal vein thrombosis, etc.). TIPS establishment was performed using an ultrasound and fluoroscope-guided technique. After successful transjugular puncture of the portal vein, a 5 French marked pigtail catheter (Cordis medical; Bloomington IN, USA) was introduced into the portal vein (PV) and advanced to the confluence (CO) of superior 
Table 1 Patient characteristics $(\mathrm{PSPG}=$ portal systemic pressure gradient; TIPS indication $\mathrm{A}=$ refractory ascites, $\mathrm{B}=$ variceal bleeding; na $=$ not assessed; MOF $=$ multi-organ failure)

\begin{tabular}{|c|c|c|c|}
\hline & Coil-only (NG) & Glue + -Coil (G) & Sig \\
\hline No & 64 & 40 & \\
\hline Mean age & $58.16(\mathrm{SD} 11.1)$ & $52.43(\mathrm{SD} 13.5)$ & $P=0.02$ \\
\hline Male/female & $41 / 23$ & $26 / 14$ & $P=0.92$ \\
\hline MELD & $11.65(\mathrm{SD} 5.0)$ & $10.57(\mathrm{SD} 6.5)$ & $P=0.72$ \\
\hline \multicolumn{4}{|l|}{ Child-Pugh grading } \\
\hline $\mathrm{Na}$ & 4 & 5 & \\
\hline A & 20 & 11 & \\
\hline B & 25 & 16 & \\
\hline $\mathrm{C}$ & 15 & 8 & $P=0.71$ \\
\hline PSPG pre-TIPS & $20.41(\mathrm{SD} 6.93)$ & 20.93 (SD 6.72) & $P=0.71$ \\
\hline PSPG post-TIPS & $8.93($ SD 5.7) & $10.23(\mathrm{SD} 5.35)$ & $P=0.25$ \\
\hline Bilirubin at TIPS & 1.58 & 1.39 & $P=0.52$ \\
\hline INR at TIPS & 1.2 & 1.2 & $P=0.74$ \\
\hline Creatinine at TIPS & 0.95 & 0.89 & $P=0.75$ \\
\hline TIPS indication (A/B) & $\mathrm{A}=23 ; \mathrm{B}=41$ & $\mathrm{~A}=10 ; \mathrm{B}=30$ & $P=0.25$ \\
\hline Hepatic encephalopathy (1 year) & $22 / 64(34 \%)$ & $15 / 40(38 \%)$ & $P=0.75$ \\
\hline Rebleeding (1 year) & $6 / 64(9 \%)$ & $3 / 40(8 \%)$ & $P=0.74$ \\
\hline Gastro-/splenorenal shunt & 4 & 3 & $P=0.55$ \\
\hline \multicolumn{4}{|l|}{ GEV grading (endoscopic) } \\
\hline $\mathrm{Na}$ & 14 & 14 & \\
\hline 1 & 10 & 5 & \\
\hline 2 & 23 & 10 & \\
\hline 3 & 14 & 10 & \\
\hline 4 & 3 & 1 & $P=0.81$ \\
\hline \multicolumn{4}{|l|}{ Causes of death } \\
\hline MOF & 3 & 0 & $P=0.28$ \\
\hline Septic shock & 5 & 2 & $P=0.70$ \\
\hline GEV bleeding & 3 & 2 & $P=1.0$ \\
\hline Liver failure & 10 & 2 & $P=0.12$ \\
\hline Total & 21 & 6 & $P=0.035$ \\
\hline
\end{tabular}

Table 2 Inclusion and exclusion criteria for TIPSS placement and GEV embolization (HPVG = hepatic portal venous gradient

\begin{tabular}{lll}
\hline & Inclusion & Exclusion \\
\hline TIPS placement & Recurrent GEV bleeding & HPVG $<10 \mathrm{mmHg}$ \\
& Refractory ascites & Severe hepatic encephalopathy \\
& & Bilirubin blood concentration $>2 \mathrm{mg} / \mathrm{dl}$ \\
GEV embolization & Persistent GEV filling on angiogram after TIPSS establishment & No filling of GEV after TIPSS in patients \\
\hline
\end{tabular}

mesenteric vein (SMV) and splenic vein (SV) to perform initial pressure measurement and contrast angiography (at $\mathrm{CO}$ and in SV) to assess gastroesophageal varices and length of stent to be placed. Shunt establishment was performed by deployment of a PTFE-covered stent (Gore Viatorr endoprosthesis, W.L. Gore Medical, Flagstaff, Arizona, USA). Dilatation of the stent was done according to the portosystemic pressure gradient (PSPG) to achieve an adequate decrease in PSPG with a target of 8-12 mmHg. After TIPS creation, an 5F pigtail catheter is placed into the $\mathrm{SV}$ and a standardized contrast angiography (flow: $15 \mathrm{ml} / \mathrm{s}$; contrast volume: $30 \mathrm{ml}$ ) is performed. If varices were still present, embolization of these was performed using 3-14-mm (0.035 in) pushable coils (Cook medical), glue (mixture (1:3) of n-butyl-cyanoacrylate (Histoacryl, B. Braun AG, Melsungen, Germany) and 
Fig. 1 Patient inclusion-TIPS procedures with PTFE-covered stent

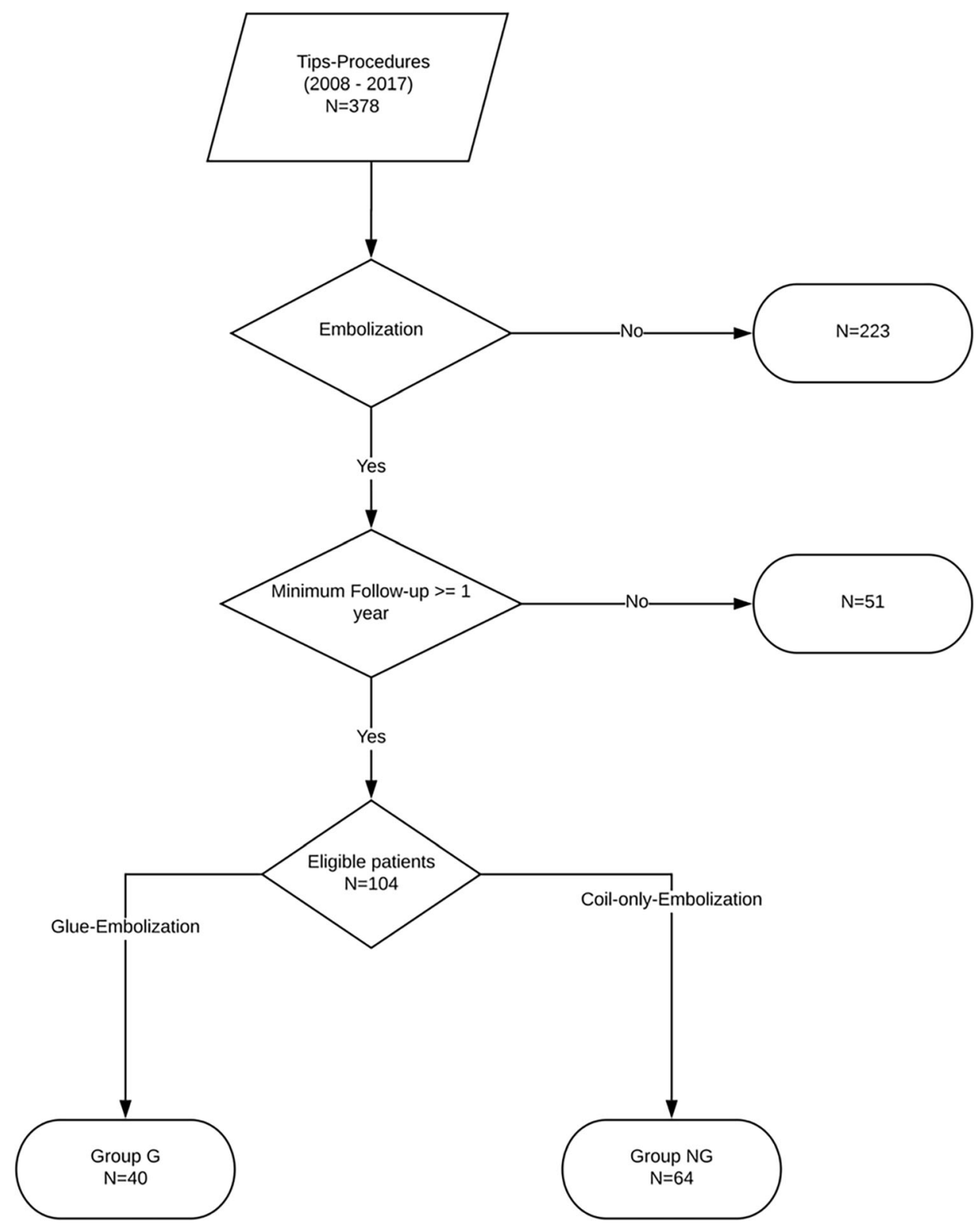

lipiodol (Guerbet medical; Paris; France), or both at the discretion of the interventionist. A 4F catheter was placed into the varices and either glue was injected, or coils have been pushed through the catheter. In combined embolization first some coils have been inserted into the varices in order to reduce flow and prevent the then applied glue from "floating away" into the azygos vein and lungs. Embolization was performed until the varicose veins could not be detected on contrast angiography performed at the same site and equal standardized injection parameters.

\section{Results}

\section{Patient cohort}

Patient characteristics are shown in Table 1. Mean age was 55.93 years (SD 12.51). Patients were predominantly male (64\%) with a mean MELD of 12.59 (SD 5.39). Child-Pugh stage did not show sig. differences between groups $(P=0.71)$. Indications for TIPS establishment were refractory ascites $(n=33)$ and variceal bleeding $(n=71)$. CT scans prior to embolization discerned 7 splenorenal shunts $(n=4 \mathrm{NG} ; n=3 \mathrm{G} ; p=0.55)$. In 76 patients endoscopic evaluation prior to TIPS was performed 
(Table 1) without significant differences between both groups $(P=0.81)$.

Embolization was performed using glue $(n=40)$ (group G) or coils-only $(n=64)$ (group NG, no glue). In 18 patients coils and n-butyl-cyanoacrylate were employed. There was no observed difference in PSPG (NG: $8 \mathrm{mmHg}$; $\mathrm{G}: 10 \mathrm{mmHg} ; p=0.12$ ) and portal venous pressure (NG: $19 \mathrm{mmHg}$; G: $21 \mathrm{mmHg} ; p=0.49$ ) after TIPSS. On

Table 3 Results of multivariate and univariate analysis ( $\mathrm{PAR}=$ patients at risk; HR = hazard ratio; $\mathrm{PSP}=$ portosystemic pressure gradient; $\mathrm{PVP}=$ portal venous pressure)

\begin{tabular}{|c|c|c|c|c|c|c|c|c|}
\hline \multirow{3}{*}{ Overall survival $(1$ year $)(P A R=27}$, & \multicolumn{4}{|c|}{ Univariate } & \multicolumn{4}{|c|}{ Multivariate } \\
\hline & \multirow[t]{2}{*}{ HR } & \multicolumn{2}{|l|}{$95 \% \mathrm{CI}$} & \multirow[t]{2}{*}{ Sig } & \multirow[t]{2}{*}{ HR } & \multicolumn{2}{|c|}{$95 \% \mathrm{CI}$} & \multirow[t]{2}{*}{ Sig } \\
\hline & & & & & & & & \\
\hline \multicolumn{9}{|l|}{ Group } \\
\hline NG & 2.483 & 1.002 & 6.155 & 0.042 & 3.333 & 1.193 & 9.312 & 0.022 \\
\hline G & \multicolumn{4}{|c|}{ Reference } & \multicolumn{4}{|c|}{ Reference } \\
\hline Patient age (years) & 1.050 & 1.012 & 1.090 & 0.009 & 1.052 & 1.009 & 1.096 & 0.017 \\
\hline MELD score & 1.108 & 1.054 & 1.166 & $<0.001$ & 1.144 & 1.072 & 1.220 & $<0.001$ \\
\hline PSP gradient after TIPS (mmHg) & 0.980 & 0.907 & 1.060 & 0.622 & & & & \\
\hline PSP gradient before TIPS (mmHg) & 0.980 & 0.907 & 1.060 & 0.259 & & & & \\
\hline PVP after TIPS (mmHg) & 1.015 & 0.960 & 1.075 & 0.595 & & & & \\
\hline PVP before TIPS (mmHg) & 0.974 & 0.922 & 1.030 & 0.361 & & & & \\
\hline \multicolumn{9}{|l|}{ Variceal bleeding before TIPS } \\
\hline No & 1.001 & 0.449 & 2.228 & 0.998 & 0.757 & 0.330 & 1.740 & 0.513 \\
\hline Yes & \multicolumn{4}{|c|}{ Reference } & \multicolumn{4}{|c|}{ Reference } \\
\hline \multicolumn{9}{|l|}{ Overall survival $(6$ weeks $)(P A R=16)$} \\
\hline \multicolumn{9}{|l|}{ Group } \\
\hline NG & 2.898 & 0.826 & 1.017 & 0.097 & 6.945 & 1.492 & 32.333 & 0.014 \\
\hline GG & \multicolumn{4}{|c|}{ Reference } & \multicolumn{4}{|c|}{ Reference } \\
\hline Patient age (years) & 1.032 & 0.986 & 1.081 & 0.17 & 1.026 & 0.974 & 1.080 & 0.337 \\
\hline MELD score & 1.157 & 1.085 & 1.234 & $<0.001$ & 1.224 & 1.112 & 1.347 & 0.000 \\
\hline PSP gradient after TIPS (mmHg) & 0.986 & 0.890 & 1.092 & 0.791 & & & & \\
\hline PSP gradient before TIPS (mmHg) & 0.963 & 0.886 & 1.048 & 0.383 & & & & \\
\hline PVP after TIPS (mmHg) & 1.059 & 0.986 & 1.138 & 0.114 & & & & \\
\hline PVP before TIPS (mmHg) & 1.019 & 0.947 & 1.096 & 0.618 & & & & \\
\hline \multicolumn{9}{|l|}{ Variceal bleeding before TIPS } \\
\hline No & 0.447 & 0.127 & 1.570 & 0.209 & 0.383 & 0.105 & 1.403 & 0.148 \\
\hline Yes & \multicolumn{4}{|c|}{ Reference } & \multicolumn{4}{|c|}{ Reference } \\
\hline \multicolumn{9}{|l|}{ ACLF (6 months) $(\mathrm{PAR}=20)$} \\
\hline \multicolumn{9}{|l|}{ Group } \\
\hline NG & 1.576 & 0.606 & 4.103 & 0.351 & 3.243 & 1.062 & 9.900 & 0.039 \\
\hline G & Referer & & & & Refere & & & \\
\hline Patient age (years) & 1.020 & 0.983 & 1.059 & 0.291 & 1.017 & 0.971 & 1.065 & 0.477 \\
\hline MELD score & 1.180 & 1.110 & 1.253 & $<0.001$ & 1.228 & 1.135 & 1.328 & 0.000 \\
\hline PSP gradient after TIPS (mmHg) & 0.969 & 0.882 & 1.064 & 0.504 & & & & \\
\hline PSP gradient before TIPS (mmHg) & 0.944 & 0.877 & 1.016 & 0.125 & & & & \\
\hline PVP after TIPS (mmHg) & 1.033 & 0.970 & 1.100 & 0.315 & & & & \\
\hline PVP before TIPS (mmHg) & 0.997 & 0.936 & 1.061 & 0.914 & & & & \\
\hline Variceal bleeding before TIPS & & & & & & & & \\
\hline No & 0.653 & 0.237 & 1.797 & 0.409 & 0.509 & 0.178 & 1.455 & 0.208 \\
\hline Yes & Referer & & & & Refere & & & \\
\hline
\end{tabular}


average 8.34 coils have been used in group NG and 2.9 coils in group $\mathrm{G}(p=<0.0001)$. No difference in mean fluoroscopy time could be observed $(\mathrm{NG}=35.28 \mathrm{~min}$; $\mathrm{G}=34.36 \mathrm{~min} ; p=0.87$ ).

\section{Embolization and mortality}

Results of univariate and multivariate analysis are shown in Table 3. Univariate analysis showed significant influence on overall survival for age $(p=0.01)$, MELD at TIPS $(p=0.001)$ as well as the MELD score subparameters (serum bilirubin $(p=0.001)$ and creatinin $(p=0.002)$ and INR $(p=0.017))$ as significantly associated with overall survival. The indication for TIPS (i.e., refractory ascites and recurrent GEV bleeding) did not show any correlation $(p=0.998)$ but has been described as influential in prior studies [6].

To account for these potential confounders Cox regression adjustment for TIPS indication (refractory ascites/variceal bleeding), age and MELD score was performed. Causes of death are shown in Table 1. Patients who received coil-only embolization (group NG) had significantly higher (21 deaths) one-year mortality compared to group $\mathrm{G}(6$ deaths $)(\mathrm{p}=0.022 ; \mathrm{HR}=3.33)$ (Fig. 2). Six-week survival as a surrogate of treatment failure was significantly lower in group NG $(n=13)$ compared to group $\mathrm{G}(n=3) \quad(p=0.014 ; \mathrm{HR}=6.95)$ (Fig. 3). Development of ACLF was significantly higher in group NG after 6 months (NG: $n=14 ; \mathrm{G}: n=6$ ) $(p=0.039 ; \mathrm{HR}=3.24)$ (Fig. 4).

A subgroup Kaplan-Meier analysis of subgroups with variceal bleeding $(n=71)$ and refractory ascites $(n=33)$ as TIPS indication showed 18 deaths in the variceal bleeding subgroup (NG: $n=13$ (est. surv: 264d) vs. G: $n=5$ (est. surv: $317 \mathrm{~d}$ ); $p=0.135$ ) within one year and 13 deaths within six weeks after TIPS (NG: $n=10$ (est. surv: 34d) vs. G: $n=3$ (est. surv: 39d); $p=0.116$ ). ACLF during the first six months showed no significant difference $(n=15 ; \mathrm{NG}=9$ (est. ACLF free time $=4.9 \mathrm{mo})$ vs. $\mathrm{G}=6$ (est. ACLF free time $=5 \mathrm{mo}$ ); $p=0.733$ ).

In the sub-cohort with refractory ascites as TIPS indication group $\mathrm{G}$ showed a trend for longer 1-year survival compared to group NG (NG: $n=8$ (est. surv: 267d) vs. G: $n=1$ (est. surv: $352 \mathrm{~d}$ ); $p=0.142$ ) and at six months (NG:
Fig. 2 One-year mortality analysis glue vs coil-only embolization $(\mathrm{p}=0.022$; $\mathrm{HR}=3.33)(\mathrm{mo}=$ months $)$

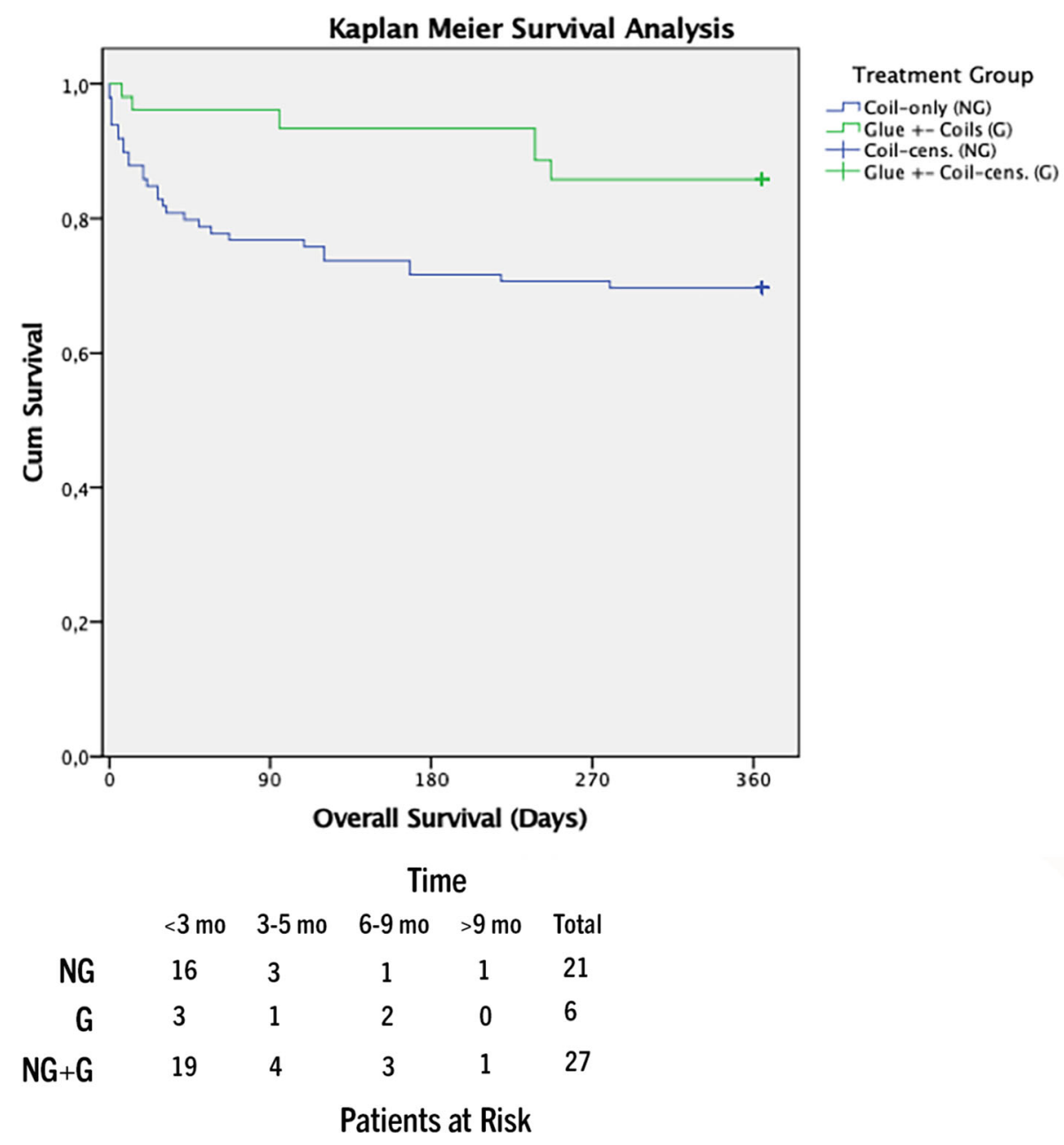


Fig. 3: Six-week mortality analysis glue vs coil-only embolization $(\mathrm{p}=0.014$; $\mathrm{HR}=6.95)($ we $=$ weeks $)$

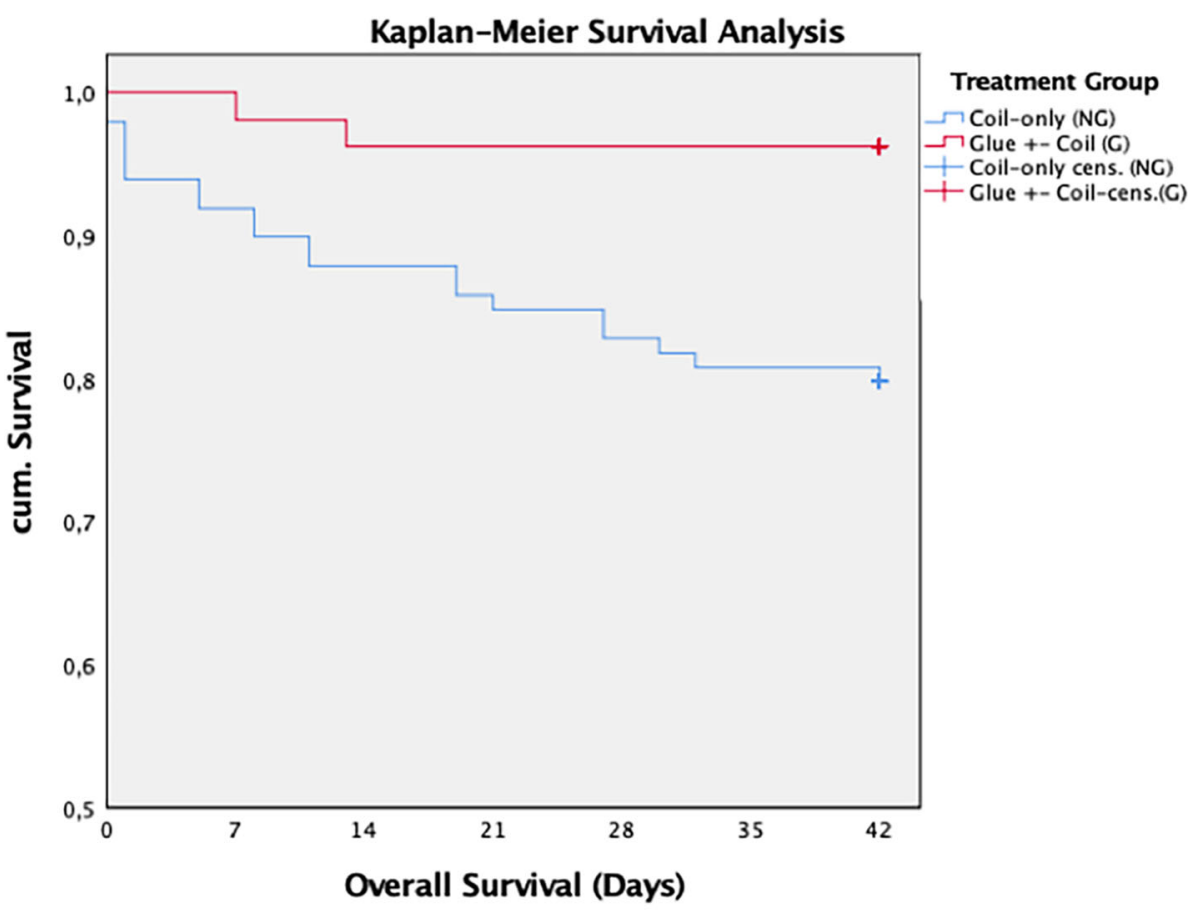

$n=3$ vs. G: $n=0 ; p=0.243$ ) in the glue group could also be observed. Also, development of ACLF during 6 months was non-significantly more pronounced in the NG subgroup ( $\mathrm{NG}=5 ; \mathrm{G}=0 ; p=0.107)$.

However, in all of these sub-evaluations no significant difference could be seen, probably due to the reduced patient number in each sub-cohort.

\section{Embolization and complications}

Occurrence of episodes of HE as defined by West Haven criteria in group $\mathrm{G}$ and group NG was not significantly different $(15(37 \%)$ vs. $22(34 \%) ; p=0.75)$ during oneyear follow-up. Rebleeding rates in both groups (G: $n=3$; NG: $n=6 ; p=0.74$ ) were very low as expected. However, rebleeding was fatal in some cases $(\mathrm{G}: n=2 ; \mathrm{NG}=3$; $p=0.94)$.

Post-TIPS CT scans were not routinely performed. However, on performed post-TIPS CT scans small glue material particles were found inside the lungs in group $\mathrm{G}$. None of the cases had clinical signs of pulmonary embolism (CIRSE grade 1).
One severe non-target embolization in group $\mathrm{G}$ was observed. Glue material caused paradox embolism into the brain via a patent foramen ovale and caused an non-fatal stroke. The patient died from septic complications during the follow-up period (CIRSE grade 5).

No adverse events have been reported in group NG.

\section{Discussion}

The present study evaluated the concomitant use of fluid embolization of GEV during TIPS compared to coil-only embolization.

It is an established fact that closure of GEV in patients with variceal bleeding in combination with TIPS lowers rebleeding rates [13, 24]. Moreover, recent data suggest presence of SPSS impacts outcome of cirrhotic patients [15], suggesting that efficient, overall shunt reduction is warranted in this patient group. However, different embolization materials (fluid and non-fluid) may show differences regarding their overall effectiveness [10]. 
Fig. 4 Acute-on-chronic liver failure (CLIF-ACLF)—glue vs coil-only embolization $(\mathrm{p}=0.039 ; \mathrm{HR}=3.24)$ $(\mathrm{mo}=$ months $)$

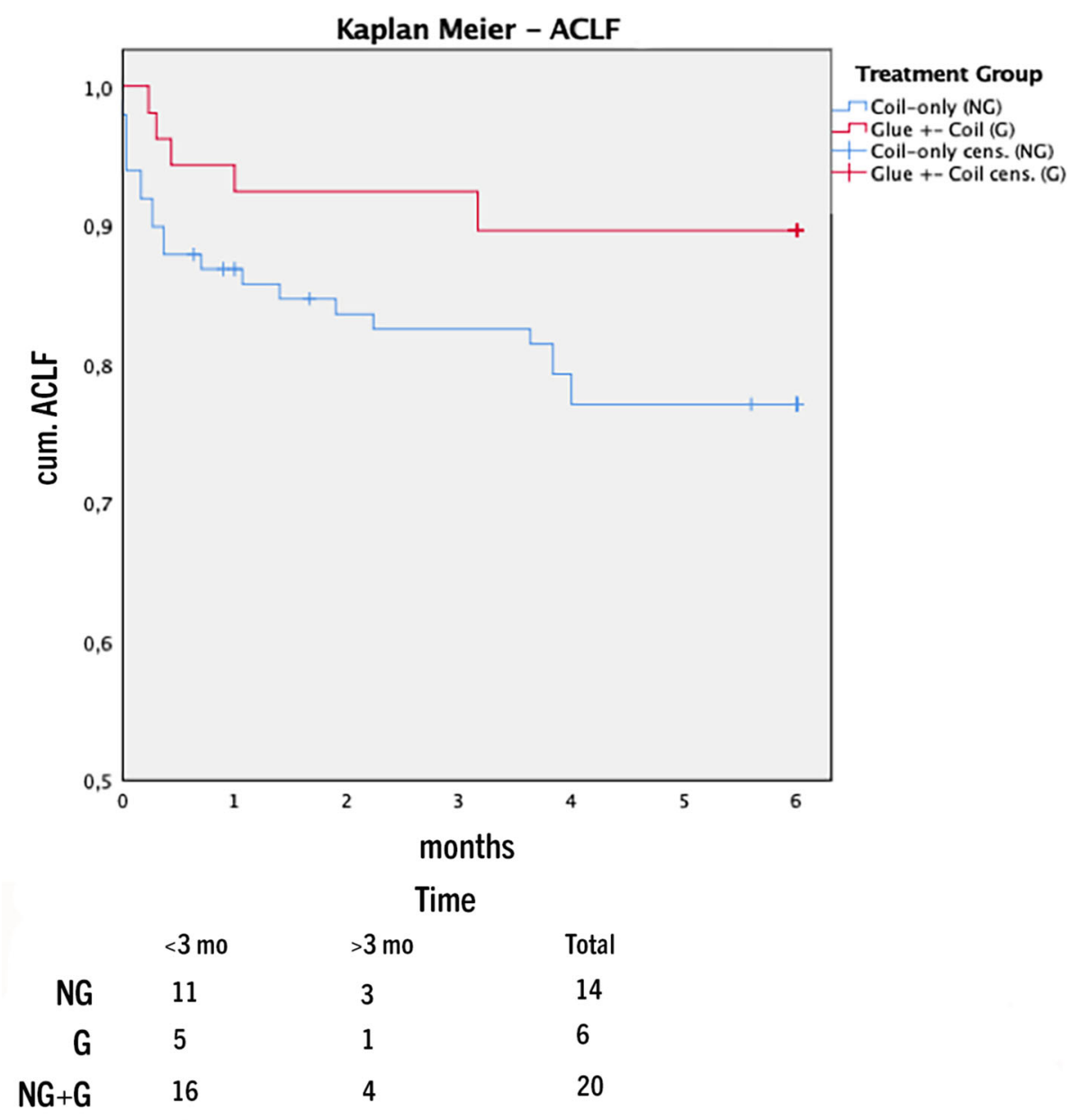

Patients at Risk
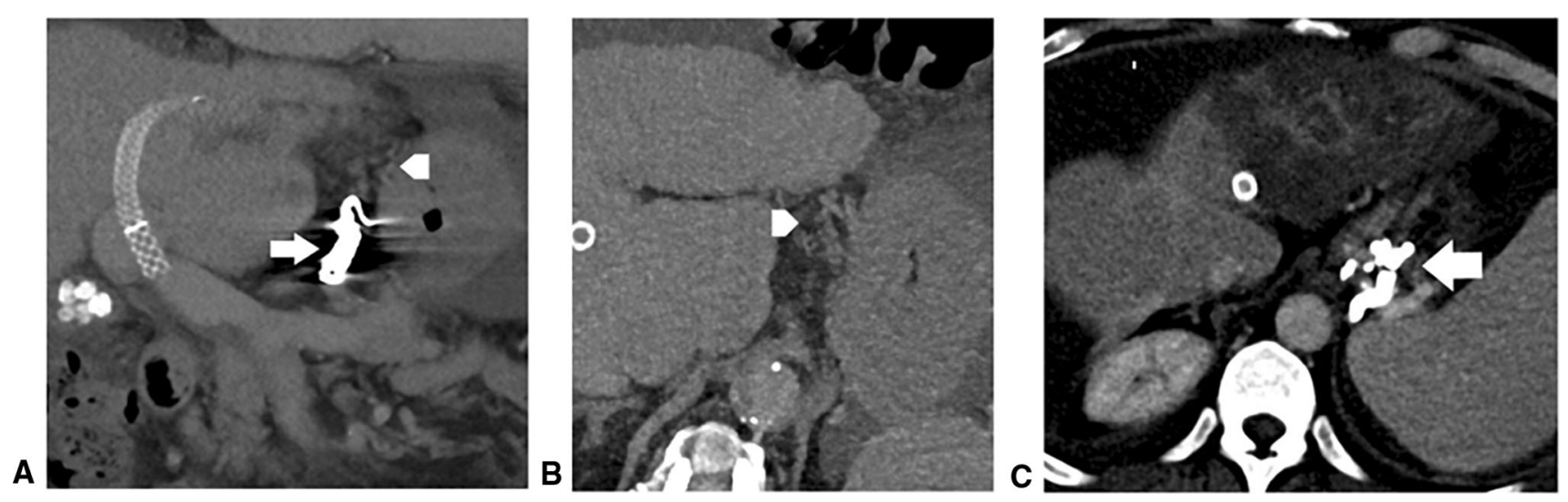

Fig. 5 a-c: (a) CT after coil embolization of coronal vein (arrow) with distal not closed varix vessels (arrowhead) (cor. MPR); (b) distally not closed varix vessels (arrowhead) (ax); (c) CT after glue embolization of varix vessels forming "cast-like" formation (arrow)

Our data suggest that embolization of gastroesophageal varices with fluid embolization material (i.e., a mixture of n-butyl-cyanoacrylate and lipiodol) during TIPS establishment may reduce mortality, treatment failure and may also slow deterioration of liver function compared to coilonly embolization.

One explanation for this finding may be due to the physical characteristics of fluid embolization materials 
Fig. $6 \mathrm{a}+\mathrm{b}$ : Contrast angiography showing large variceal network prior (a) and after glue embolization (b)
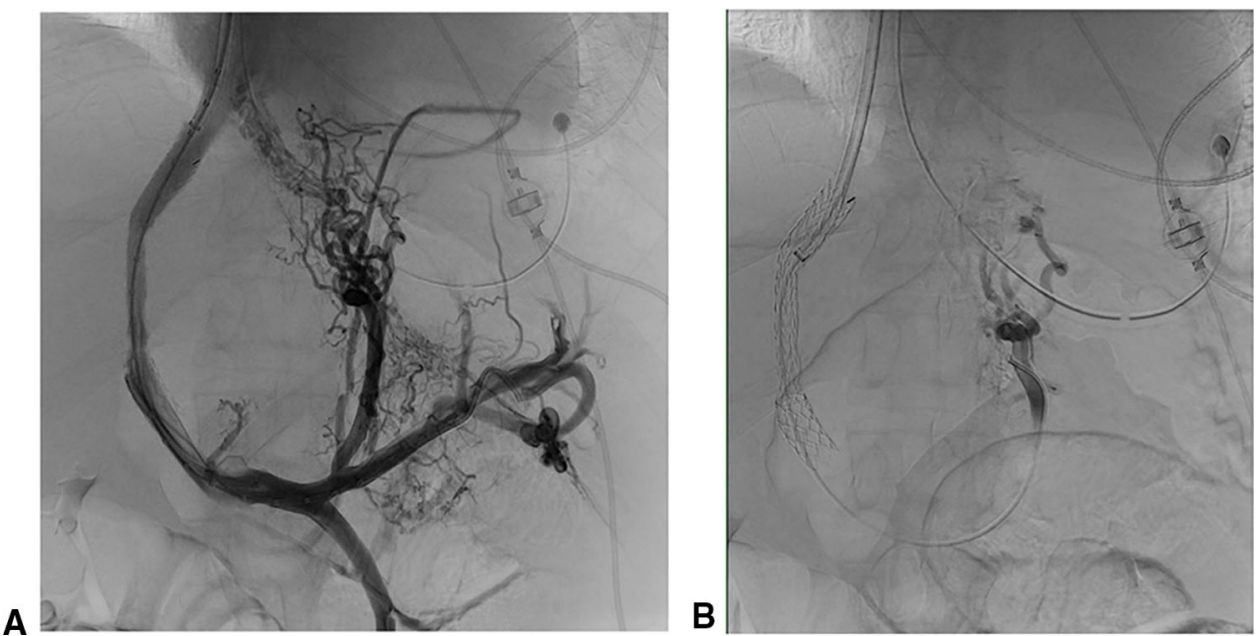

which disseminate into the network of GEV collaterals more easily and thoroughly - thus, leading to a cast-like formation accumulating in the periphery of GEV. In contrast, coil embolization facilitates a local closure only in major inflow vessels, where coils are deployed, but not the entire variceal network (Figs. 5, 6). Therefore, this embolization method might be more prone to incomplete occlusion of the inflow into EVs and refilling of the GEV from other collateral portal feeder vessels. This is supported by previously published work by Lakhoo et al. [17] in which the authors describe that in patients who underwent embolization of GEV without usage of glue embolization (i.e., coil and plug embolization), $65 \%$ of the varices remained patent, which was likely due to recruitment of other afferent supplying vessels to the variceal network after successful closure of the primary inflow vessel.

Therefore, persisting portosystemic shunting with coilonly embolization might be a feasible pathophysiological explanation for our results, which are further substantiated by previous studies which did show that patients with TIPS and patent portosystemic collaterals exhibited worse rebleeding and HE rates [15, 24, 25].

Surprisingly, although according to our data the examined groups differed in one-year survival, a significant difference in rebleeding rate could not be observed. This is in concordance with previous published data showing that reduction of rebleeding is only one of many factors TIPS influences mortality in the follow-up period [6].

It has been shown that TIPS increases effective blood volume and therefore improves systemic hemodynamics and increases renal perfusion [26]. Blood contained in GEV is also lost to effective systemic vascular flow; thus, reduction of GEV volume accomplished by cast-like glue embolization filling may further contribute to systemic hemodynamics as compared to coil-only embolization.
In our cohort there was no significant difference in rates of $\mathrm{HE}$ episodes between both embolization methods. In fact, recently it has been shown that HE rates were not different between closed and not embolized/patent varices in TIPS patients, which is supported by our results [24]. Moreover, a recent study suggested that higher HE rates are only found in patients after TIPS who had large $(>8 \mathrm{~mm}$ diameter) patent spontaneous portosystemic shunts (SPSS). In patients whose SPSS have been small, no significant worsening of HE-specific outcome could be seen [14]. It is therefore conceivable that regarding HE rates full cessation of flow inside GEV is not necessary and embolization of major GEV-feeding vessels is able to sufficiently reduce flow to reduce HE rates regardless of material employed.

On the other hand, usage of fluid embolization materials especially glue is more challenging in application. Also, these materials are more prone to major complication and non-target embolization. Coils are more precise and easier to apply especially if detachable coils are used. In summation employment of glue needs more experience and specialized training. Also prices of glue and coils (pushable and detachable) in different countries may vary significantly so that decision for either embolization method needs to take these regional conditions into account.

Our study has several limitations. Firstly, even though these patients were from the prospective NEPTUN cohort, this is a retrospective analysis. We examined a heterogeneous group of patients with different indications for TIPS (refractory ascites and variceal bleeding), which carry a different overall prognosis. It is known that these indication groups feature a different overall prognosis [6]. Furthermore, the NG group was older compared to the G group. However, we addressed these confounders in this work by adjusting the Cox regression analysis. Although our results are convincingly significant, further studies consisting in a more homogenous population would be desirable. 
Randomized prospective matched cohorts are desirable and should be done in further studies but are difficult to obtain in an interventional emergency setting.

Additionally, embolization method selection was performed at the operator's discretion. This was mainly in regard to material availability of lipiodol and correctly sized coils as well as proficiency of material preparation by the radiology assistant personnel. This may introduce a slight selection bias. However, since these influencing factors have been independent of the patient, it is therefore conceivable that the impact on procedure outcome should be evenly distributed between the groups.

Although we took great efforts in standardizing our embolization approach regarding which GEV to embolize and when embolization is finished (standardized catheter positions and contrast injection parameters), the nature of portal hemodynamics introduces a slight fuzziness in these definitions. Since this is independent of embolization method, it is valid to assume that there should be no influence on outcome parameter evaluation comparing glue usage.

Also, some data which could be influential on outcome could not be validly assessed in all cases. Endoscopic grading of GEV prior to TIPS was not possible in 28 cases, and distinct quantitative parameters of GEV (diameter, etc.) have not been assessed. Since not sig. difference between groups in GEV grading could be observed, it is assumable that the remaining cases would show an equivalent distribution.

Another limitation has been that some data which may have given us more understanding of embolization effectiveness like volume of glue injected, DAP, success of ascites control have not been thoroughly validly documented. Therefore, some opportunities of gaining insight have been missed and should be captured in further prospective studies.

Although clinical apparent and initial complications were documented, occult non-significant adverse events, like small lung emboly, have been registered only incidentally on random post-TIPS CT scans and not logged quantitatively. These should be done in more standardized fashion in further investigations.

\section{Conclusion}

In conclusion this study shows for the first time that closure of gastroesophageal varices in patients undergoing TIPS utilizing glue embolization material may improve overall survival and may be preferable over coil embolization alone.
Funding Open Access funding enabled and organized by Projekt DEAL.

\section{Declarations}

Conflict of interest All authors state that they have no conflict of interest to declare.

Ethical approval All procedures performed in studies involving human participants were in accordance with the ethical standards of the institutional and/or national research committee and with the 1964 Helsinki Declaration and its later amendments or comparable ethical standards. Institutional review board approval was obtained.

Informed consent Informed consent was obtained from all individual participants included in the study.

Consent for publication For this type of study consent for publication is not required.

Open Access This article is licensed under a Creative Commons Attribution 4.0 International License, which permits use, sharing, adaptation, distribution and reproduction in any medium or format, as long as you give appropriate credit to the original author(s) and the source, provide a link to the Creative Commons licence, and indicate if changes were made. The images or other third party material in this article are included in the article's Creative Commons licence, unless indicated otherwise in a credit line to the material. If material is not included in the article's Creative Commons licence and your intended use is not permitted by statutory regulation or exceeds the permitted use, you will need to obtain permission directly from the copyright holder. To view a copy of this licence, visit http://creativecommons. org/licenses/by/4.0/.

\section{References}

1. Williams R, Aspinall R, Bellis M, Camps-Walsh G, Cramp M, Dhawan A, et al. Addressing liver disease in the UK: a blueprint for attaining excellence in health care and reducing premature mortality from lifestyle issues of excess consumption of alcohol, obesity, and viral hepatitis. Lancet. 2014;384:1953-97.

2. Sheron N. Alcohol and liver disease in Europe-simple measures have the potential to prevent tens of thousands of premature deaths. J Hepatol. 2016;64:957-67.

3. Bosch J, Abraldes JG, Berzigotti A, García-pagan JC. The clinical use of HPVG measurements in chronic liver disease. Nat Rev Gastroenterol Hepatol. 2009;6:573-82.

4. Kleber G, Sauerbruch T, Fischer G, Paumgartner G. Pressure of intraoesophageal varices assessed by fine needle puncture: its relation to endoscopic signs and severity of liver disease in patients with cirrhosis. Gut. 1989;30:228-32.

5. Angeli P, Bernardi M, Villanueva C, Francoz C, Mookerjee RP, Trebicka J, et al. EASL Clinical Practice Guidelines for the management of patients with decompensated cirrhosis. J Hepatol. 2018;69:406-60.

6. Trebicka J. Does transjugular intrahepatic portosystemic shunt stent differentially improve survival in a subset of cirrhotic patients? Semin Liver Dis. 2018;38:87-95.

7. García-Pagán JC, Caca K, Bureau C, Laleman W, Appenrodt B, Luca A, et al. Early use of TIPS in patients with cirrhosis and variceal bleeding for the early TIPS (transjugular intrahepatic portosystemic shunt) cooperative study group. N Engl J Med. 2010;362:2370-9. 
8. Thabut D, Pauwels A, Carbonell N, Remy AJ, Nahon P, Causse $\mathrm{X}$, et al. Cirrhotic patients with portal hypertension-related bleeding and an indication for early-TIPS: a large multicentre audit with real-life results. J Hepatol. 2018;68:73-81.

9. Wolter K, Decker G, Kuetting D, Trebicka J, Manekeller S, Meyer $\mathrm{C}$, et al. Interventional treatment of acute portal vein thrombosis. RöFo - Fortschritte auf dem Gebiet der Röntgenstrahlen und der Bildgeb Verfahren. 2018;190:740-6.

10. Qi X, Liu L, Bai M, Chen H, Wang J, Yang Z, et al. Transjugular intrahepatic portosystemic shunt in combination with or without variceal embolization for the prevention of variceal rebleeding: a meta-analysis. J Gastroenterol Hepatol. 2014;29:688-96.

11. Pereira K, Carrion AF, Salsamendi J, Doshi M, Baker R, Kably I. Endovascular management of refractory hepatic encephalopathy complication of transjugular intrahepatic portosystemic shunt (TIPS): comprehensive review and clinical practice algorithm. Cardiovasc Intervent Radiol. 2016;39:170-82.

12. Laleman W, Simon-Talero M, Maleux G, Perez M, Ameloot K, Soriano G, et al. Embolization of large spontaneous portosystemic shunts for refractory hepatic encephalopathy: a multicenter survey on safety and efficacy. Hepatology. 2013;57:2448-57.

13. Tang Y, Zheng S, Yang J, Bao W, Yang L, Li Y, et al. Use of concomitant variceal embolization and prophylactic antiplatelet/ anticoagulative in transjugular intrahepatic portosystemic shunting: a retrospective study of 182 cirrhotic portal hypertension patients. Med (United States). 2017;96.

14. He C, Lv Y, Wang Z, Guo W, Tie J, Li K, et al. Association between non-variceal spontaneous portosystemic shunt and outcomes after TIPS in cirrhosis. Dig Liver Dis. 2018

15. Simón-Talero M, Roccarina D, Martínez J, Lampichler K, Baiges A, Low G, et al. Association Between Portosystemic Shunts and Increased Complications and Mortality in Patients With Cirrhosis. Gastroenterology. 2018;154:1694-1705.e4.

16. Praktiknjo M, Simón-Talero M, Römer J, Roccarina D, Martínez J, Lampichler K, et al. Total area of spontaneous portosystemic shunts independently predicts hepatic encephalopathy and mortality in liver cirrhosis. J Hepatol. 2020;72:1140-50.

17. Lakhoo J, Bui JT, Peter Lokken R, Ray CE, Gaba RC. Transjugular intrahepatic portosystemic shunt creation and variceal coil or plug embolization ineffectively attain gastric variceal decompression or occlusion: results of a 26-patient retrospective study. J Vasc Interv Radiol. 2016;27:1001-11.

18. Sarwar A, Esparaz AM, Tapper EB, Brook OR, Grunwald D, Malik R, et al. Comparison of vascular plugs and pushable coils for variceal embolization after TIPS. Am J Roentgenol. 2017;208:650-5.

19. Jansen C, Möller P, Meyer C, Kolbe CC, Bogs C, Pohlmann A, et al. Increase in liver stiffness after transjugular intrahepatic portosystemic shunt is associated with inflammation and predicts mortality. Hepatology. 2018;67:1472-84.

20. Praktiknjo M, Lehmann J, Nielsen MJ, Schierwagen R, Uschner FE, Meyer C, et al. Acute decompensation boosts hepatic collagen type III deposition and deteriorates experimental and human cirrhosis. Hepatol Commun. 2018;2:211-22.

21. Lehmann J, Praktiknjo M, Nielsen MJ, Schierwagen R, Meyer C, Thomas D, et al. Collagen type IV remodelling gender-specifically predicts mortality in decompensated cirrhosis. Liver Int. 2019;39:885-93.

22. Moreau R, Jalan R, Gines P, Pavesi M, Angeli P, Cordoba J, et al. Acute-on-chronic liver failure is a distinct syndrome that develops in patients with acute decompensation of cirrhosis. Gastroenterology. 2013;144:1426-1437 e9.

23. Sarin SK, Valla DC, De FR. Revising consensus in portal hypertension: report of the baveno $\mathrm{v}$ consensus workshop on methodology of diagnosis and therapy in portal hypertension. J Hepatol. 2011;54:1082-3.

24. Yu J, Wang X, Jiang M, Ma H, Zhou Z, Yang L, et al. Comparison of transjugular intrahepatic portosystemic shunt ( TIPS ) alone and combined with embolisation for the management of cardiofundal varices:a retrospectiv stud. 2018;

25. Chen S, Li X, Wei B, Tong H, Zhang M-G, Huang Z-Y, et al. Recurrent variceal bleeding and shunt patency: prospective randomized controlled trial of transjugular intrahepatic portosystemic shunt alone or combined with coronary vein embolization. Radiology. 2013;268:900-6.

26. Rössle M. TIPS: 25 years later. J Hepatol. 2013;59:1081-93.

Publisher's Note Springer Nature remains neutral with regard to jurisdictional claims in published maps and institutional affiliations. 